A DIvision of research in the history of medicine and public health has been established at the Institute of Public Health Research. The new division has the following objectives: (1) research in the history of medicine and public health in general, with special reference to oriental medicine; (2) to reveal valuable contributions by early physicians to the world of medicine; (3) to compare and inter-relate ancient and modern medicine, and to study the major works of early physicians; (4) to prepare and publish books and pamphlets in these fields; (5) to edit and publish old texts of medicine and demonstrate their significance. Dr. M. Najm-Abadi, lecturer in the history and ethics of medicine, Teheran University, and General Secretary to the Iranian Association of the History of Sciences and Medicine, is in charge of the new division. He and his staff are most anxious to establish scientific and cultural exchange with other institutions throughout the world. Reprints and books relevant to the work of the new department would be most gratefully received, and should be addressed to: Institute of Public Health Research (Historical Division), University of Teheran, P.O. Box 1310, Teheran, Iran.

\title{
THE WELLCOME TRUST
}

THE Wellcome Trustees have invited the following international group to form a Panel to advise them upon their support for the history of medicine, under the chairmanship of Lord Cohen of Birkenhead, Professor W. C. Gibson (Vancouver), Mr. F. Greenaway (Science Museum), Professor A. R. Hall (Imperial College), Dr. Charles Newman (Royal College of Physicians) and Professor J. Steudel (Bonn University). Dr. F. N. L. Poynter has accepted an invitation to act as an Assessor for the Panel; Lord Murray of Newhaven will represent the Trustees, and Dr. P. O. Williams will act as Secretary.

THE Trustees have also decided that it would be more in keeping with the status and functions of their Historical Medical Museum and Library if it were renamed the Wellcome Institute of the History of Medicine. The Institute, which is based on the personal collection of Sir Henry S. Wellcome, holds the most comprehensive Museum and Library of the History of Medicine in the world, and is an international research centre for this subject. The Trustees are at present expanding the accommodation for the Museum.

\section{MACCABAEAN PRIZE ESSAY, 1968}

THE Maccabaean Prize and Medal of the Faculty of the History of Medicine and Pharmacy at the Worshipful Society of Apothecaries of London has been awarded to Dr. Charles Warren (Cambridge and Guy's) for his essay on 'Aspects of Medicine in the Greek Bronze Age.' In view of the high standard of entries this year, the Faculty has also awarded a second prize of ten guineas to Dr. R. Gillon (Oxford and 